\title{
LA SOCIOLOGÍA DE ORTEGA*
}

Jorge Acevedo

Ortega se dedicó a múltiples ocupaciones durante su vida; pero todas se centraban alrededor de la que para él fue la principal: la filosofía. Su vocación pensante absorbió la mayor parte de su tiempo y energías. Aunque su esfuerzo filosófico ha sido recogido en doce gruesos volúmenes de Obras Completas - que todavía no lo son del todo-, Ortega, como ya insinuamos, no fue un pensador que permaneciera normalmente en su gabinete de trabajo; por el contrario, participó de manera muy activa en los problemas y conflictos sociohistóricos de la colectividad en que vivía. De ahí que los resultados a los que llegó, intelectualmente, respecto de la sociedad y la historia -entidades inseparables que se com-plican mutuamente-, sean producto, también, de la experiencia directa que tuvo de fenómenos idénticos o semejantes a los que describe o alude.

Su paso por la política no fue suficientemente "afortunado", como suele ocurrir con los intelectuales que incursionan en su ámbito". No obstante, aunque la república española que resultó fue muy distinta de la que él anhelaba y por la que luchó ${ }^{2}$, las vivencias que obtuvo en un campo de asuntos diametralmente opuesto al que le era propio, fueron fructíferas. Su "fracaso" dentro de la política decantó en una serie de meditaciones sociológicas e históricas $-y$, por cierto, políticas-que

* Este escrito forma parte de un proyecto de investigación FONDECYT (Clave: 1180-90).

1 Cfr., de Gonzalo Redondo, Las empresas políticas de José Ortega y Gasset, Eds. Rialp, Madrid, 1970.

2 Cfr., de Julián Marías, "España inteligible. Razón histórica de las Españas", Alianza Editorial, Madrid, 1985; Cap. xxVII: España como desorientación creadora entre dos naufragios. Del mismo autor: Una vida presente. Memorias 1 (1914-1951). Alianza Ed., Madrid, 1989; en especial, Caps. $x y$ ss. Además, la Sección Quinta -El Naufragio- de su "Ortega * "Las trayectorias", Alianza Ed., Madrid, 1983. 
son de la mayor importancia. Experiencias desdichadas se tradujeron en teorias de gran significación. Ortega, fiel a su ética, sacó provecho inclusive -y muy especialmente- de lo insatisfactorio, obstaculizador, negativo y aporético.

Muy diferente entre sí, los contactos de Heidegger, Ortega y Sartre con la política, tienen algo en común: son deslucidos, discutidos y discutibles, y atrajeron sobre los protagonistas una retahíla de dificultades personales. A pesar de ello son, de maneras diversas, fecundos para nosotros, puesto que de esas "fuentes" podemos aprender mucho. Por lo pronto, los diversos modos de insertarse el intelectual en la política. En mi opinión, sólo Ortega participó de verdad en ella, o si se quiere, sólo él intervino en la política "de verdad". Sartre y Heidegger, cada uno en su estilo, se movieron meramente en su periferia.

El pensamiento histórico-social de Ortega se mueve sobre el fundamento, dado por supuesto, de una próte philosophia o filosofía primera, cuyo punto de partida no es la subjetividad, el yo puro o la consciencia, sino la vida humana, entendida como el enfronte entre un programa vital -el hombre- y la circunstancia en que procura realizarse ${ }^{3}$. Lo que primariamente hay no es, pues, una inmanencia especular que se limita, por sobre todo, a conocer, sino, más bien, lo contrario: un choque, un conflicto, una confrontación, una pugna; en suma, un drama. Esta palabra no debe entenderse como una simple metáfora, sino como un término técnico que designa la realidad radical, esto es, aquella realidad en la que, por ser raíz de las demás, todas las otras tienen que aparecer polémicamente ${ }^{4}$. El vivir es, en efecto, pólemos, lucha, tanto en el plano personal como en el colectivo.

Cada ser humano no sólo debe ganarse la vida en el sentido usual de la expresión, sino que también tiene que hacerlo en un plano previo: metafísico, ontológico o entitativo (tómese como válida cualquiera de estas palabras, u otra equivalente que resulte aceptable y no chocante). $Y$ para ello hay que luchar, aunque en algunos casos - como el del mismo Ortega ${ }^{5}$ - la lucha consista, paradójicamente, en el establecimiento y organización de una paz perdurable.

La idea de lucha - y recuérdese a Heráclito, a propósito de esto- nos sirve, como hemos dicho, para dar cuenta, también, del estrato primario de la existencia histórico-social. Así como el drama personal estriba en el denodado esfuerzo de dar realidad, en una determinada circunstancia, a un proyecto de sí mismo, el drama colectivo es, por lo pronto, la lucha entre las generaciones históricas que configuran una sociedad ${ }^{6}$. No queremos decir con esto que la única lucha social sea la de

Véase, del autor, "Hombre y Mundo. Sobre el punto de partida de la filosofía actual", Ed. Universita. ria, Santiago, 1984.

4 Véase, del autor, "Vivir como acontecer, categoría fundamental de la historia"; en Anuario de Filosofia Juridica y Social No 2, Edeval, Valparaiso (Chile), 1984

5 Cfr., de Ortega, Idea del Teatro. Obras Completas, vol. vil, Ed. Revista de Occidente, Madrid; p. 443.

6 Véase, del autor, "Notas sobre la estructura empírica de la vida humana y el método histórico de las 
las generaciones; sólo afirmamos - siguiendo a Ortega-que ella es la constitutiva de la historia. Esto significa que queda abierta la posibilidad de que haya otras - la de clases, por ejemplo- que modulen a la generacional y que, desde ciertos puntos de vista o en algunas situaciones, tengan mayor "impacto" (transitoriamente, al menos) que ella.

Una de las principales preocupaciones teoréticas de Ortega estuvo constituida por lo que podríamos Ilamar "meditación del conflicto"; así, por ejemplo, cabe interpretar su obra Del Imperio Romano desde esta perspectiva. Escrita en la Argentina, presumo que fue elaborada por su autor teniendo ante la vista, entre otros fenómenos, tanto la Guerra Civil Española como la Segunda Guerra Mundial, que desde el punto de vista de Ortega tendría que denominarse, más bien, Segunda Gran Guerra Civil Europea. Su meta fue elaborar algo así como una teoría desde la cual fuera posible poner el conflicto bajo cierto "control"; más precisamente, su finalidad consistió en mostrar caminos que hicieran del conflicto algo fecundo, de tal modo de evitar que la lucha social aniquilara, de uno u otro modo, a los contrincantes, y con ellos, a la colectividad en su conjunto.

Para Ortega, toda sociedad es siempre, a la par, di-sociedad; constantemente hay en ella lucha y cooperación; pretender que en su seno hay sólo lo uno o lo otro es deformar su realidad, no dar cuenta cabal de ella. También es un error creer que la sociedad se autorregula, bastando "dejar hacer, dejar pasar" para que los asuntos marchen satisfactoriamente. La crítica que Ortega dirige al liberalismo clásico - que es sólo una forma de liberalismo - respecto de este punto es fuerte. "Hay - dice - el hecho de que los hombres conviven, pero esa convivencia no es nunca efectivamente sociedad; es, simplemente, conato o esfuerzo, más o menos intenso, para llegar a serlo, cuando no es todo lo contrario: descomposición y desmoronamiento de una relativa socialización antes lograda. La sociedad, conste, es tan constitutivamente el lugar de la sociabilidad como el lugar de la más atroz insociabilidad, y no es en ella menos normal que la beneficencia, la criminalidad. [...] Todas las cautelas, todas las vigilancias son pocas para conseguir que en alguna medida predominen las fuerzas y modos sociales sobre los antisociales. EI liberalismo [clásico], en cambio, creía que no había que hacer nada, sino, al contrario, laisser faire, laisser passer" ${ }^{\prime \prime}$. Por cierto, Ortega también hace contundentes objeciones a la postura opuesta: el estatismo a ultranza. Recordemos que el capítulo XIII de La rebelión de las masas se titula "El mayor peligro, el Estado", y en

generaciones, según Julián Marias"; en Anuario de Filosofia Juridica y Socia/ No 7, EDEVAL, Valparaiso, 1989.

7 Al respecto, véase, por ejemplo, de Julián Marías, "La experiencia de la vida"; en El tiempo que ni vuelve ni tropieza. Obras Completas, vol. vil, Ed. Revista de Occidente, Madrid, pp. 647 y s.

$8 \quad$ Cfr., Del Imperio Romano. O.C., vi, p. 73. 
él, entre otras cosas, Ortega señala esto: 1. "En nuestro tiempo, el Estado ha llegado a ser una máquina formidable, que funciona prodigiosamente; de una maravillosa eficiencia por la cantidad y precisión de sus medios. Plantada en medio de la sociedad, basta tocar a un resorte para que actúen sus enormes palancas y operen fulminantes sobre cualquier trozo del cuerpo social". 2. "Este es el mayor peligro que hoy amenaza a la civilización: la estatificación de la vida, el intervencionismo del Estado, la absorción de toda espontaneidad social por el Estado; es decir, la anulación de la espontaneidad histórica, que en definitiva sostiene, nutre y empuja los destinos humanos"

Si las posturas extremas frente al problema que nos ocupa quedan descalificadas, tendrá que haber una postura mesurada que sería preciso adoptar. Pero esta postura no puede ser enunciada en fórmulas radicalmente simplificadoras, como la del liberalismo clásico - "dejar hacer, dejar pasar" - o la del fascismo italiano: "Todo por el Estado; nada fuera del Estado; nada contra el Estado" 10 . Por lo pronto, de ella habría que decir que tendría que estar, en cada caso, condicionada por la peculiar situación histórica que vive en cierto instante determinada sociedad. Por ende, en ella se dejaría de vivir desde el punto de vista de la eternidad para vivir desde el punto de vista del instante ${ }^{11}$.

En su libro Naturaleza, Historia, Dios distingue Zubiri dos concepciones del tiempo ${ }^{12}$. La primera, vigente hasta el siglo XVIII, lo concibe como una sucesión de presentes. Para ella, el pasado ya fue, ya pasó y, por tanto, ya no es. El pretérito, pues, queda a la espalda del hombre, se pierde. El pasado - para esta interpretación de lo temporal-es algo que pasó a otros y que carece de realidad, se entiende, de realidad presente, la única que hay. La entidad del pasado es mínima, y depende de los hombres presentes. En efecto, estos podrían reactualizarlo, en cierto modo y hasta cierto punto, a través del recuerdo. Pero si ello no acontece, el pretérito se hunde en la nada, o poco menos. Esta dimensión del tiempo dependería de nuestra voluntad para poder ser.

Precisemos - manteniéndonos en esa perspectiva - la carencia de realidad del pasado. Si entendemos por realidad "aquello con que contamos, queramos o no" -esto es, "la contravoluntad, lo que nosotros no ponemos; antes bien, aquello con

10 En La rebelión de las masas - O.C., iv, p. 226-Ortega cita esta frase, y la somete a crítica junto a lo que representa.

11 Al respecto, véase, Del Imperio Romano. O.C., vi, p. 55. Del mismo Ortega, "Pidiendo un Goethe desde dentro". O.C., iv, p. 416. Además, "Prólogo a una Edición de sus Obras". O.C., vi, p. 348.

12 Véase, dentro de esta obra - cuya novena edición ha sido publicada por Alianza Ed. y la Sociedad de Estudios y Publicaciones en Madrid, el año 1987-, la segunda parte, 'Nuestra actitud ante el pasado', del capítulo "El acontecer humano: Grecia y la pervivencia del pasado filosófico" (pp. 362 y ss.). 
que topamos"13-, entonces, el pasado no sería real para tal concepción del tiempo, porque su entidad aparecería sólo cuando nos ponemos expresamente a recordarlo; la existencia del pasado estaría en nuestra mano.

Para esa concepción del pasado, la ocupación con éste tiene, en el mejor de los casos, sólo una función ética: al hombre actual le convendría saber cómo se comportaron sus congéneres en situaciones pretéritas análogas.

Pero desde el siglo XVIII comienza a imponerse otra interpretación del tiempo que, al ser muy diferente de la anterior, acarreará consecuencias innovadoras de variada índole. Por lo pronto, se distingue en ella entre tiempo cósmico lo de la materia) y tiempo vital (o del espíritu) ${ }^{14}$. En aquél -el tiempo cósmico-el pasado ya pasó y el futuro aún no acontece; de este modo, ni el pretérito ni el porvenir tienen, propiamente, realidad, no son presentes. Si en el ámbito cósmico hallamos algo así como un pasado y un futuro, el uno y el otro le advienen desde el hombre. Sea dicho de paso: desde el punto de vista de Ortega, un planteamiento así es perfectamente explicable. Tomemos en cuenta que para este pensador la vida humana es la realidad radical, es decir, aquella en que, necesariamente, aparecen todas las demás ${ }^{15}$; entre ellas, por cierto, el cosmos (o la materia); de esa manera, todo - también lo cósmico- es, de algún modo, humano.

El tiempo vital -en rigor, el de la vida del hombre (o del espíritu) - es profundamente distinto. En su dominio -que abarca el anterior-, el presente es -también, pero con novísimos "matices" que, en verdad, son mucho más que eso- la dimensión temporal en relación a la que se dan las otras: pasado y futuro. Pero el presente no es, para esta segunda comprensión de la temporalidad -en la que, como un punto culminante, estaría la interpretación de Ortega- un instante exento de esenciales conexiones con el pretérito y el porvenir. Todo lo contrario: el presente se compone, en buena medida, de pasado y futuro.

"El pasado confina con el futuro - señala Ortega- porque el presente que idealmente los separa es una línea tan sutil que sólo sirve para juntarlos $y$ articularlos. Al menos en el hombre, el presente es un vaso de pared delgadísima lleno

13 Cfr., de Ortega, Ideas y creencias. O.C., v, p. 389 (este libro es complemento indispensable de El hombre y la gente, en el que nos centraremos más adelante).

14 En rigor, Ortega evita los términos "materia" y "espiritu" porque piensa que no dan cuenta de $l o$ últimamente real -que es, normalmente, lo que él busca; cuando los emplea, los utiliza en un sentido lato, o de manera informal, o en una acepción bien precisa y restringida que acota expresamente. Respecto de esto, véase, por ejemplo, Hombre y Mundo, p. 44. Por otra parte, de Julián Marías, "El hombre y la gente. La teoria de la vida social en Ortega"; en La Escuela de Madrid. O.C., v, p. 434. Además, el capítulo vi de Historia como sistema, de Ortega (O.C., vi, pp. 25 y ss.).

15 Sobre el alcance y límite de esta tesis, véase, por una parte, el artículo de Marías indicado en la nota precedente. Por otra, del autor, "Una localización filosófica de la dimensión cordial del hombre"; en Revista Chilena de Neuropsiquiatria, Vol. 28, No 1, Santiago, 1990; pp. 34 y s. 
hasta los bordes de recuerdos y de expectativas. Casi, casi pudiera decirse que el presente es mero pretexto para que haya pasado y haya futuro, el lugar donde ambos logran ser tales" ${ }^{16}$. El presente, pues, es algo que se extiende, a saber: hacia el pasado y el futuro, que cooperan, decisivamente, a constituirlo. El pasado no se pierde, según esta tesis. El pasado humano pervive, en significativa proporción, configurando el ser mismo del hombre actual. El porvenir cobra la mayor importancia. Hasta tal punto esto sería así, que Ortega nos dice que "no hay [...] más remedio que definir al hombre como un ser cuya realidad primaria y más decisiva consiste en ocuparse de su futuro. Esta ocupación por adelantado con lo que aún no es, sino que amenaza ser en el instante próximo, es, por tanto, preocupación, y esto es, ante todo y por debajo de todo, la vida humana: preocupación, o como mi amigo Heidegger ha dicho, trece años más tarde que yo, Sorge, cura, es decir, preocupación"17.

Ocuparse con la historia, con el pasado humano, no tiene sólo un sentido ético; antes de tener un carácter ético, habérselas con la historia es una tarea de carácter metafísico u ontológico, en cuanto que hacer historia es descubrir el ser mismo del hombre, una dimensión de su propia realidad ${ }^{18}$. Expresamente, advierte Ortega que el pasado no es algo ajeno a nosotros, sino que "constituye nuestros propios entresijos" ${ }^{19}$. Pero, ¿de qué manera persiste el pasado en el hombre? ¿Cómo es que la historia es aún presente en el ser humano de hoy? Entre otros resultados, responder estas preguntas - que, claro está, en el fondo son sólo una- nos permitiría entender, fundadamente, por qué se dice que el hombre es una entidad histórico-social o sociohistórica.

El pasado pervive en nosotros - posibilitando, así, que seamos históricos-en nuestra dimensión social o colectiva. Esta faceta de la vida humana predomina hasta tal punto en el hombre, que Ortega ha afirmado taxativamente, que "antes que sujetos psíquicos somos sujetos sociológicos ${ }^{\prime 20}$, oponiéndose con ello a gran parte de las interpretaciones del ser humano. Para entender - al menos, parcialmente- lo que es la historia como pasado - sentido habitual del término historiadebemos, primero, esclarecer qué es sociedad.

16 Cfr., Origen y Epilogo de la Filosofia. O.C., Ix, p. 350. El recordar de que habla Ortega en este texto no debe entenderse, como se verá más adelante, en el mismo sentido, restringido, del 'recordar' al que nos referíamos al tratar la primera concepción del tiempo que examina Zubiri.

17 Cfr., "Pasado y porvenir para el hombre actual"; en el libro del mismo nombre. O.C., IX, p. 654. Acerca de la importancia del futuro en el ámbito de la "vida" colectiva, véase, del autor, "Renan, Ortega y la Idea de Nación"; en Estudios Públicos No38, Santiago, 1990.

18 Véase, del autor, "Sobre la teoría de la historia en Ortega"; en Revista de Filosofia, Vol. 33-34, Santiago, 1989.

19 Cfr., "Prospecto del Instituto de Humanidades". O.C., VII, p. 18.

20 Cfr., "La Filosofía de la Historia de Hegel y la 'Historiología' ". O.C., Iv, p. 540. 
En la Meditación de Europa de Ortega, leemos: "Una sociedad es la convivencia de individuos humanos bajo un sistema de usos" ${ }^{21}$. Procuraremos aprehender el significado de este aserto comenzando desde su final, y concentrándonos en él, esto es, refiriéndonos a los usos. Para ello recurriré, ante todo, a El hombre y la gente, obra fundamental y decisiva dentro de la sociología filosófica lo filosofía sociológical de nuestro autor, en la que hallamos, por ejemplo, los fundamentos teóricos de su famoso libro La rebelión de las masas, que, sin ellos y otros aspectos de su filosofía, resulta, en rigor, ininteligible. Alí indica, por lo pronto, que los hechos sociales constitutivos son usos ${ }^{22}$. Si queremos saber qué es sociedad tenemos, por tanto, que dirigir nuestra mirada de manera especial -aunque no exclusiva- a los usos.

Esta advertencia metodológica no está de más si tomamos en cuenta que, en el ámbito de lo humano, lo más difícil de captar es lo social, como sostiene Ortega: “Toda realidad está pronta a ocultarse - ya lo dijo Heráclito-y cada una posee un determinado coeficiente de ocultación. La cifra máxima en este poder de clandestinidad corresponde a Dios y por ello su advocación más filosófica debiera ser la de Deus absconditus [Dios oculto]. [... ] Pues bien, entre las cosas humanas es la sociedad la menos patente, la que más se disfraza detrás de otras" ${ }^{23}$.

En El hombre y la gente, Ortega se refiere a los usos, sintéticamente, de la siguiente manera: "Para la doctrina sociológica que se va a exponer en estas lecciones basta con que ciertos usos, si se quiere los casos extremos del uso, se caractericen por estos rasgos.

$\left.1^{\circ}\right)$ Son acciones que ejecutamos en virtud de una presión social. Esta presión consiste en la anticipación, por nuestra parte, de las represalias 'morales' o físicas que nuestro contorno va a ejercer contra nosotros si no nos comportamos así.

$\left.2^{\circ}\right)$ Son acciones cuyo preciso contenido, esto es, lo que en ellas hacemos, nos es ininteligible. Los usos son irracionales.

$\left.3^{\circ}\right)$ Los encontramos como formas de conducta, que son a la vez presiones fuera de nuestra persona y de toda otra persona, porque actúan sobre el prójimo lo

21 Véase, "Europa y la idea de nación (y otros ensayos sobre problemas del hombre contemporáneo)"; Revista de Occidente en Alianza Editorial, Madrid, 1985; apartado 'Opinión pública y poder público. El equilibrio europeo. El Derecho consuetudinario'; p. 90 (véase, también, p. 44). [O.C., |x, p. 293 y p. 257].

O.C., vII, p. 76 .

23 Cfr., "Prospecto del Instituto de Humanidades". O.C., VII, p. 13 (sobre el fenómeno de la ocultación, véase, de Ortega, Apuntes sobre el pensamiento [O.C., v]). Aludiendo a este hecho, Ortega dirá en El hombre y la gente: “Y aquí tenemos la causa, bien que ahora sólo enunciada y no esclarecida, de que la sociología sea la más reciente entre las ciencias de Humanidades y, claro está, la más retrasada y balbuciente" (O.C., VII, p. 205). Esto era válido, ciertamente, en la época en que Ortega enunciaba su tesis. 
mismo que sobre nosotros. Los usos son realidades extraindividuales o impersonales" 24 .

Antes de detenernos en cada una de estas características, notemos que es innecesario que todos los usos las ostenten; para que la teoría de Ortega sea válida basta con que las posean, en grado suficiente -tampoco sería imprescindible llegar en esto a lo absoluto-, los casos extremos del uso. Lo que digo es congruente con una tesis fundamental del pensamiento de este autor, a saber: "En la naturaleza no hay grados de realidad. Las cosas o son o no son, sin más. Pero es característico de lo humano poseer los grados más diversos de realidad" 25 . Lo que se relaciona con el hombre, por ende, debe ser siempre visto — no sólo en esta ocasión- de una manera gradual, alejándonos, en lo que a él se refiere, de los absolutos.

Para explicitar el primer carácter de los usos lo, al menos, de sus casos extremos) -ser imposiciones mecánicas-, es preciso remitirse, por lo pronto, al capítulo décimo de El hombre y la gente, donde el filósofo afirma: "El uso [. . .] se me aparece como la amenaza presente en mi espiritu de una eventual violencia, coacción o sanción que los demás van a ejecutar contra mí". Y agrega: "Este es el carácter con que primero se presenta en nuestra vida 'lo social'. Lo percibe antes nuestra voluntad que nuestra inteligencia. Queremos hacer o dejar de hacer algo y descubrimos que no podemos; que no podemos, porque frente a nosotros se levanta un poder, más fuerte que el nuestro, que fuerza y domeña nuestro querer" ${ }^{26}$. A este poder lo llama Ortega poder social ${ }^{27} \mathrm{y}$, también, poder público ${ }^{28}$.

Hagamos resaltar, antes de seguir adelante, algo sobremanera extraño: lo social es percibido antes por nuestra voluntad que por nuestra inteligencia. Por lo visto, la voluntad tiene, además, la capacidad de percibir; tal vez ciertas realidades - ¿o todas ellas? - sean captadas sólo cuando se conjugan, del modo apropiado, inteligencia, voluntad $y$ sentimentalidad ${ }^{29}$. Pero continuemos.

Ortega entiende por " 'coacción sobre mi comportamiento' toda consecuencia penosa, sea del orden que sea, producida por el hecho de no hacer yo lo que se hace en mi contorno social" 30 . En otras palabras: "hay coacción siempre que no podemos elegir impunemente un comportamiento distinto de lo que en la colectividad se hace"31

25 Cfr., "Prólogo a

26 O.C., VIII, p. 215.

27 lbid.

28 Ibid., pp. 267 y ss.

29 Al respecto, véase, del autor, "Una localización filosófica de la dimensión cordial del hombre".

30 Cfr., El hombre y la gente. O.C., VII, p. 236.

31 Ibid. 
La coacción puede ser débil o fuerte. Estos dos grados de energía en la coacción nos permiten clasificar los usos en "débiles y difusos", por una parte, $y$ "fuertes $y$ rígidos", por otra ${ }^{32}$. Las ilustraciones con que Ortega alude a esta distinción son esclarecedoras. "Ejemplos de los 'usos débiles y difusos' - dice- son los que vagamente se han llamado siempre 'usos y costumbres', en el vestir, en el comer, en el trato social corriente; pero son también ejemplo de ellos los usos en el decir y en el pensar, que constituye el decir de la gente, cuyas dos formas son la lengua misma y los tópicos, que es lo que confusamente se llama 'opinión pública' "33. Y añade: "Ejemplo de los 'usos fuertes y rígidos' son - aparte de los usos económicos- el derecho y el Estado, dentro del cual aparece esa cosa terrible, pero inexorable e inexcusable, que es la política" 34 .

La coacción contra el que falta al uso del saludo es casi siempre laxa; va contra el que no lo ha respetado en forma de juicios desfavorables, o actuaciones parejas, que sólo a la larga traerán para él consecuencias enojosas ${ }^{35}$. Frente a ese tipo de coacción, encontramos la coacción máxima, que es la física, y que el contorno social "practica cuando se contraviene a un tipo de usos muy característico que se llama 'derecho' "36. "Si alguien roba un reloj - acota Ortega-y es cogido in fraganti, un policía se apodera inmediatamente de él y, a la fuerza, se lo lleva a la comisaría. En este caso, pues, la respuesta de la sociedad a un abuso es física, de máxima intensidad y fulminante ${ }^{\prime 37}$.

Pero hay otras formas de coacción social o colectiva más sutiles, que no consisten en actos especiales, positivos o negativos (omisiones), que los demás ejercen contra nosotros. Ortega señala dos ejemplos que no dejan de causar sorpresa, a pesar de su aparente simplicidad o, tal vez, por ella misma. El primero es éste: "el amante quiere decir algo a su amada pero se niega a usar una determinada lengua. Evidentemente no por ello interviene la policía, pero el hecho es que entonces la amada no le entiende y él se queda sin decirle lo que deseaba. El uso que es la lengua, sin aspavientos, sin aparentes violencias, se impone a nosotros, nos coacciona de la manera más sencilla, pero más automática e inexorable del mundo, impidiendo que seamos entendidos con toda plenitud y, en consecuencia, paralizando radicalmente toda convivencia fértil y normal con el prójimo" ${ }^{38}$. El otro ejemplo se refiere a "un caso mínimo pero, por lo mismo, muy significativo: si nos resolvemos a tomar como desayuno algo distinto de lo que es el repertorio de los

Ibíd., p. 235.

Ibid., p. 228.

Ibid.

Ibid., p. 227.

lbid., p. 235.

Ibid.

lbíd., p. 236. 
desayunos usuales, se verán las dificultades que encontramos, el esfuerzo que en tal trivial cotidianidad tenemos que gastar, por ejemplo, en los viajes y cambios de residencia. La sociedad, en cambio, nos ahorra incluso el esfuerzo de inventarnos el desayuno adelantándonos el menú de los usuales" ${ }^{39}$. En este caso, pues, la punición o castigo significa, simplemente, "que no hacer lo que se hace en nuestro derredor nos obliga a un esfuerzo mayor que hacerlo" 40.

El segundo carácter de, al menos, los casos extremos del uso consiste en su ininteligibilidad, es decir, no entendemos su preciso contenido. Es lo que ocurriría, según Ortega, con el saludo, fenómeno al que dedica, por lo pronto, el capítulo ixy parte del capítulo $x$ de El hombre y la gente, dentro del segmento más directamente sociológico de la obra. Resumamos el planteamiento en sus propios términos: "Cualquiera de nosotros va a casa de alguien que es su conocido, donde sabe que va a encontrar reunidas diferentes personas también conocidas. [. . ] ¿Qué es lo primero que hago, en casa de mi amigo, al entrar en el salón donde las personas están reunidas? [ . . . ] Pues, algo estrambótico, estrambótico porque me sorprendo ejecutando una operación que consiste en que me acerco a cada una de las personas presentes, le tomo la mano, la oprimo, la sacudo y luego la abandono. Esta acción por mí cumplida se llama saludo" 41 . Ahora bien: ese hacer mío que es tomar y dar la mano no lo entiendo bien. "Yo no sé, en efecto, por qué lo primero que tengo que hacer al encontrar otros hombres algo conocidos es precisamente esta extraña operación de sacudirles la mano. [. . . ] Y me lo confirma el hecho de que, si voy al Tibet, el prójimo tibetano, en ocasión idéntica, en vez de darme la mano, gira la cabeza de lado, se tira de una oreja y saca la lengua - complicada faena cuya finalidad y sentido distan mucho de serme translúcidos" 42 .

Una objeción, de la que Ortega se hace cargo en primera instancia, surge: "Se dirá, un poco apresuradamente, que no es así, que sé por qué lo hago, pues sé que si no doy la mano a los demás, si no saludo, me tendrán por mal educado, desdeñoso, presuntuoso, etc. Esto, sin duda, es cierto y ya veremos la decisiva importancia que tiene. Pero no confundamos las cosas porque aquí está toda la cuestión. Lo que sé, lo que entiendo es que tengo que hacer eso, pero no sé, no entiendo eso que tengo que hacer" 43 . Podemos explicar, entre tanto, la decisiva importancia que tiene la mala opinión que los demás se van a formar de mí si no saludo, recordando el carácter coactivo inherente a los usos, el cual -es significativo advertirlo- amenaza siempre, a la postre, "con la eventualidad de una violencia 
Física" 44 . Rememora Ortega: "Aún no hace muchos años -en Europa-cuando alguien negaba un saludo solía recibir automáticamente una bofetada, y al día siguiente tenía que batirse a espada, sable o pistola"45.

Hay una segunda objeción que permite al filósofo referirse a cuestiones de gran relevancia dentro de su doctrina sociológica. Por ello, es necesario recoger, lo más integramente posible, tanto la objeción como la respuesta a ella: "Es casi seguro que al decir yo por vez primera que saludar tomándose las manos era un acto sin sentido, alguien pudo pensar: No; tomarse las manos tiene sentido porque de ese modo los hombres se han asegurado mutuamente que no llevan armas en ellas. Pero - respondo - es evidente que, cuando nosotros acudimos hoy a una fiesta social o a una reunión académica no nos preocupa el temor de que los otros hombres, nuestros conocidos, lleven en sus manos lanzas, jabalinas, puñales, flechas, boomerangs. [...] Hubo un tiempo [...] en que los hombres sentían, efectivamente, ese temor, y por ello determinaron acercarse en esa forma que para ellos tenía sentido [...]. Pero esta observación [...] lo que demuestra es que tomarse las manos tuvo sentido, no que lo tiene ahora para nosotros. [...] a los usos les es constitutivo haber perdido su sentido; por tanto, haber sido en un tiempo acciones humanas interindividuales e inteligibles, acciones con alma, y haberse luego vaciado de sentido, haberse mecanizado, automatizado, como mineralizado, en suma, desalmado. [.. . ] Mi imaginario objetante confundía lo que [...] nos pasaba cuando damos la mano al saludar, que es algo sin sentido, con una teoría que él tiene sobre el origen de este hecho [...], para encontrarle ese sentido" 46 .

Podríamos distinguir, por ende, tres momentos en los casos extremos de los usos sociales. $\left.1^{\circ}\right)$ Actualmente son supervivencias, humanos petrefactos irracionales. $2^{\circ}$ ) En el instante de sus origenes fueron por el contrario, "auténticas vivencias humanas" 47 'plenas' de sentido y 'perfectamente' inteligibles. $3^{\circ}$ ) Mediante una teoría tenemos, respecto de ciertos usos, la posibilidad de recobrar ahora, de alguna manera, el sentido que tuvieron prístinamente. A esta teoría Ortega la denomina razón histórica o razón narrativa ${ }^{48}$, y siguiendo sus insinuaciones, cabría llamarla, también, razón etimológica ${ }^{49} y$, con las debidas precisiones, razón semántica ${ }^{50}$. Comprobamos así, sea dicho de paso, que a los hechos sociales constitutivos

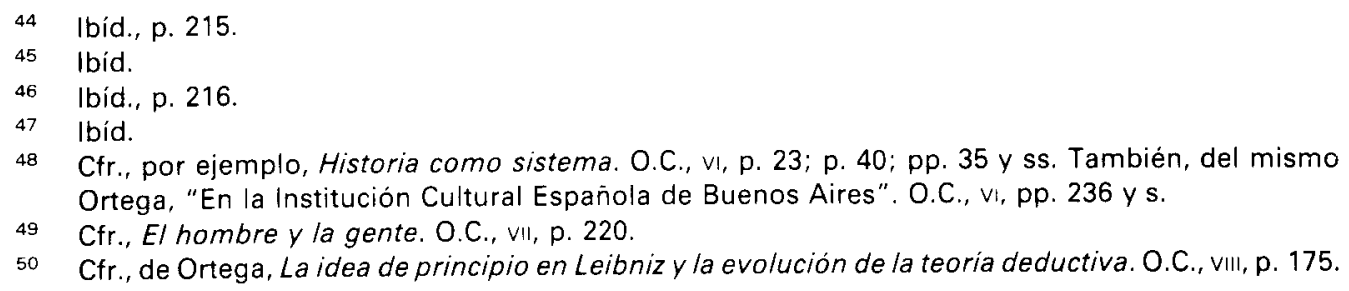


les es esencialmente inherentes la necesidad de un pensamiento histórico que verse sobre ellos. La sociología y la historia son inseparables. Con fundamento puede afirmar Ortega, y en ello encontramos una radicalización de lo que recién postulábamos, que "la historia es, ante todo, historia de las colectividades, historia de las sociedades - por tanto, historia de los usos" ${ }^{\prime 5}$.

El tercer carácter de, al menos, los casos extremos de los usos sociales estriba en que son realidades extraindividuales o impersonales. "Cuando salimos a la calle -dice Ortega-, si queremos cruzar de una acera a otra, por lugar que no sea en las esquinas, el guardia de la circulación nos impide el paso" ${ }^{\prime 2}$. ¿Qué clase de fenómeno es éste? Ciertamente, no es ni personal ni interindividual ${ }^{53}$. En efecto, "el acto en que el guardia nos prohíbe el paso no se origina espontáneamente en él, por motivos personales suyos, y no lo dedica a nosotros de hombre a hombre. En cuanto hombre e individuo, tal vez prefiera el buen gendarme ser amable con nosotros y permitirnos la travesía, pero se encuentra con que no es él quien engendra sus actos; ha suspendido su vida personal, por tanto, su vida estrictamente humana, y se ha transformado en un autómata que se limita a ejecutar lo más mecánicamente posible actos ordenados en el reglamento de circulación" 54 . Remontándonos hacia el origen de este acto prohibitivo, partimos de tal reglamento y pasamos por el guardia, el director de Policía, el ministro del Interior y el Jefe del Estado, para llegar, finalmente, al Estado mismo ${ }^{55}$. En esta ocasión, baste sugerir sobre él que esta entidad social - "acaso la más social de todas" 56 - es todo, la sociedad, la colectividad, nadie determinado ${ }^{57}$.

Vemos, por lo tanto, a través de este ejempio, que el uso social ínsito en la conducta prohibitiva del policía tiene una raíz - y un cariz-impersonal o extraindividual; por otra parte, cae con toda su fuerza tanto sobre mí como sobre el que me impide el paso $y$, más en general, sobre todos los que se encuentran en una situación semejante.

Del autor, "Historiografia e Historiología o Metahistoria (en la perspectiva del racio-vitalismo)"; en Cuadernos de Historia N $^{\circ}$ 9, Santiago, 1989

51 Cfr., El hombre y la gente. O.C., vil, p. 226.

52 Ibid., p. 197.

53 Sobre las diferencias - y mutuas referencias-entre lo personal, lo interindividual y lo propiamente social, véase, por lo pronto, la Introducción o Abreviatura de El hombre y la gente. Además, su capítulo II (por ejemplo: O.C., vII, p. 114), su capitulo $\times$ (por ejemplo: O.C., vil, pp. 202 y ss.) -del cual recojo esta frase clave: lo social aparece, no como se ha creido hasta aqui y era demasiado obvio, oponiéndolo a lo individual, sino por contraste con lo inter-individual-, y su capítulo $\times(O . C$. , vil, pp. 212 y ss.)

54 Cfr., El hombre y la gente. O.C., vil, p. 204.

55 Ibid.

56 Ibíd., p. 105.

57 Ibíd., p. 198. 
Otro ejemplo que proporciona Ortega para, entre otras cosas, ilustrar este tercer carácter del uso social, y que es de la mayor importancia, se refiere a lo que pensamos y decimos (aunque, finalmente, al explicitarlo, lo amplíe a todo hacer nuestro; luego, prácticamente a casi todas las dimensiones de la vida); "si hacemos balance - advierte- de las ideas u opiniones con las cuales y desde las cuales vivimos, hallamos con sorpresa que su mayor parte no ha sido pensado nunca por nosotros con plena y responsable evidencia, sino que las pensamos porque las hemos oído y las decimos porque se dicen". Aquí aparece, continúa el filósofo, "el impersonal se que significa, sí, alguien, pero con tal que no sea ningún individuo determinado. Este se de nuestra lengua es estupefaciente [ . . ]: nombra un alguien que es nadie. [ . . . En Erancés la cosa aparece aún más clara: por se dice emplea el 'on dit'. El impersonal es aquí on -que, como es sabido, no es sino la contracción y residuo de homo, hombre-, de modo que explicando el sentido del 'on dit' tenemos: un hombre que no es ningún hombre determinado, y como los hombres son siempre determinados - son éste, ése, aquél-, un hombre que no sea un hombre" ${ }^{15}$. Y llegando a una conclusión muy parecida a la que expone Heidegger en el parágrafo 27 de Ser y Tiempo - El cotidiano ser-sí-mismo y el se (das Man)-, culmina sus consideraciones acerca de lo que nos ocupa señalando que "lo grave cuando hacemos nosotros lo que se hace y decimos lo que se dice es que, entonces, el se, ese hombre inhumano, ese ente extraño, contradictorio, lo llevamos nosotros dentro y lo somos" 59 .

El temple o tono de lo expuesto con anterioridad puede condensarse en estos dos enérgicos párrafos, que aparecen en el centro de la meditación orteguiana sobre lo propiamente social dentro de El hombre y la gente: 1. "Resulta, pues, que vivimos, desde que vemos la luz, sumergidos en un océano de usos, que estos son la primera y más fuerte realidad con que nos encontramos: son sensu stricto nuestro contorno o mundo social, son la sociedad en que vivimos. Al través de ese mundo social o de usos, vemos el mundo de los hombres y de las cosas, vemos el Universo" ${ }^{60}$. 2. "En nuestro contorno no [hay] sólo minerales, vegetales, animales y hombres. [Hay] además, y en cierto modo antes que todo eso, otras realidades que son los usos. Desde nuestro nacimiento nos envuelven y ciñen por todos lados; nos oprimen y comprimen, se nos inyectan e insuflan; nos penetran y nos llenan casi hasta los bordes, somos de por vida sus prisioneros y sus esclavos" 61 .

Hemos presentado un tanto bruscamente estas ideas porque, sobre todo, aluden sólo a un aspecto de los usos colectivos; exagerando, podríamos calificarlo

Ibíd., p. 206

Ibíd.

Ibíd., p. 211.

Ibíd., p. 212. 
de su dimensión oscura, poco atractiva: se trata de un lado de los usos que no despierta nuestra simpatía hacia ellos. Pero si nos atenemos exclusivamente a él - como erróneamente se ha hecho cuando se ha clasificado a Ortega, sin más, entre los filósofos individualistas-, no daremos cuenta de lo que más me interesa destacar en este escrito: la profunda ambigüedad de los usos sociales. Es el momento, por tanto, de ir girando la mirada hacia otra faceta de estas potentes realidades. Para ello recurriremos a la idea - cuyo linaje, por cierto, es jurídico-de vigencia. Los usos $-\mathrm{y}$ las creencias - son vigencias colectivas.

Para Ortega, la idea de vigencia es alfa y omega de toda la sociología. Según él, "sus dos más acusados caracteres son estos: $1^{\circ}$ ) que la vigencia social, sea del origen que sea, no se nos presenta como algo que depende de nuestra individual adhesión, está ahi, tenemos que contar con ella y ejerce, por tanto, sobre nosotros su coacción; pues ya es coacción el simple hecho de que, queramos o no, tengamos que contar con ella; $2^{\circ}$ ) viceversa, en todo momento podemos recurrir a ella como a una instancia de 'poder' en qué apoyarnos" ${ }^{2}$. Los usos son, también, plataforma que nos sostiene y ayuda. Así, por ejemplo, las formas corteses de trato con los demás, las leyes del derecho, el lenguaje, la opinión pública de la colectividad en que vivo; todo ello puede operar en mi favor. Más aún: sin nuestra dimensión social, no alcanzariamos el nivel de humanidad que nos corresponde. Ortega alude a esta decisiva función vital de los usos sociales -en cuyo extraordinario alcance no se solía hacer hincapié cuando se examinaba su doctrina, pese a su importancia ontológica fundamental-, al enumerar, apretada y certeramente, las tres principales categorías de efectos que producen en el individuo: "1 ${ }^{\circ}$ ) Son pautas del comportamiento que nos permiten prever la conducta de los individuos que no conocemos $y$ que, por tanto, no son para nosotros tales determinados individuos. La relación interindividual sólo es posible con el individuo a quien individualmente conocemos, esto es, con el prójimo (=próximo). Los usos nos permiten la casi -convivencia con el desconocido, con el extraño. $2^{\circ}$ ) Al imponer a presión un cierto repertorio de acciones - de ideas, de normas, de técnicas- obligan al individuo a vivir a la altura de los tiempos e inyectan en él, quiera o no, la herencia acumulada en el pasado. Gracias a la sociedad el hombre es progreso e historia. La sociedad atesora el pasado. $3^{\circ}$ ) Al automatizar una gran parte de la conducta de la persona y darle resuelto el programa de casi todo lo que tiene que hacer, permiten a aquélla que concentre su vida personal, creadora y verdaderamente humana, en ciertas direcciones, lo que de otro modo sería al individuo imposible. La sociedad sitúa al hombre en cierta franquía frente al porvenir y le permite crear lo nuevo, racional y más perfecto" ${ }^{\prime 63}$.

62

62 lbid., p. 266.

63
Ibid., p. 78. Sobre el concepto de 'altura de los tiempos', véase, del autor, "Notas sobre el origen de 
En resumen, los usos sociales posibilitan que tengamos, en algún grado, un trato expedito con los hombres que no nos son cercanos. Por otra parte, impiden que cada hombre - o cada generación - inaugure la historia de la 'Humanidad', partiendo desde cero; antes bien, nos ponen en cierto nivel histórico -el que corresponde a las fechas en las que vivimos-- desde el cual cabe seguir avanzando (el animal, por el contrario, siempre tiene que partir desde 'la nada'; al no ser un ente histórico, no puede progresar; está constantemente iniciando su 'animalidad'64). En tercer término, concede al individuo los márgenes necesarios para que lo mejor de él se despliegue, explaye y desarrolle. Así como no habría sociedad sin individuos que convivan, no habrian, propiamente, individuos sin sociedad.

"Según esto - podríamos concluir con Ortega--, la sociedad, la colectividad, sería el medio esencial ineludible para que el hombre sea hombre. Pero entiéndase bien: cuanto hay en la sociedad vino de individuos y en ella se desindividualiza para hacer posibles nuevos individuos. Lo colectivo, pues, es algo intercalado entre las vidas personales, que de ellas nace y en ellas desemboca. Su papel, su rango, con ser constitutivo del hombre, es simplemente papel y rango de medio, de utensilio y aparato; por tanto, secundario al papel y rango de la vida personal. A lo que creo, esta concepción trascendería todas las opiniones hasta ahora sustentadas en que se contraponen individualismo y colectivismo o en que se intenta turbiamente armonizarlos" 65 .

la actitud filosófica, la cultura y la Universidad (en la perspectiva de Ortega)"; en Comunicación y Medios $\mathrm{N}^{\circ}$ 6. Santiago, 1988 (especialmente, la p. 60 ).

64 Al respecto, véase Historia como sistema. O.C., vi, p. 43.

65 Cfr., "Un rasgo de la vida alemana". O.C., v, p. 203. (Respecto de la importancia que podría tener una filosofía como la de Ortega en el ámbito de la sociología, véase, entre otras obras, Sociologismo y existencialismo, de Edward Tiryakian; Amorrortu editores, Buenos Aires, 1969). 